\title{
Effects of sample width on flame spread over horizontal charring solid surfaces on a plateau
}

\author{
ZHANG Ying, JI Jie, HUANG XinJie \& SUN JinHua* \\ State Key Laboratory of Fire Science, University of Science and Technology of China, Hefei 230027, China
}

Received September 29, 2010; accepted January 4, 2011

\begin{abstract}
Experiments were conducted on the Tibetan Plateau to investigate the effects of sample width $(W)$ on flame spread over horizontal charring solid surfaces. The results show that the rate of spread is influenced by the combined effects of convection heat transfer and flame radiation. Moreover, two different regimes depending on sample width were found in flame spread behavior. The rate of spread decreased with width in the convective regime $(W \leqslant 3 \mathrm{~cm})$ but increased in the radiative regime $(W>3 \mathrm{~cm})$. Similar results were observed in comparative experiments conducted on a plain in Hefei, with the rate of spread reaching its minimum value at $W=4 \mathrm{~cm}$ rather than $3 \mathrm{~cm}$.
\end{abstract}

plateau, flame spread, width effect, the rate of spread

Citation: $\quad$ Zhang Y, Ji J, Huang X J, et al. Effects of sample width on flame spread over horizontal charring solid surfaces on a plateau. Chinese Sci Bull, 2011, 56: 919-924, doi: 10.1007/s11434-011-4386-2

Flame spread over solid surfaces is a common phenomenon in fire accidents. Studying flame spread behavior is useful in predicting fire growth. Many studies have been conducted to explore the characteristics of flame spread. However, most research on flame spread over wood surfaces has been conducted on plains; few studies on the characteristics of flame spread on high plateaus have been reported, especially at altitudes over $3000 \mathrm{~m}$. Recent research indicated that ignition times of wood at altitude might be shorter [1] than at sea level and the combustion temperature of the flame might be higher [2], which means that fire accidents on plateaus might be potentially more hazardous. Conducting further research on the characteristics of flame spread over wood surfaces on high plateaus could provide basic data and ultimately benefit fire control and prevention at higher altitudes.

Much of the surface flame spread experiments were conducted on a laboratory scale owing to limitations in experimental conditions. To apply these small-scale experimental results to real large-scale fire situations, scale effects

*Corresponding author (email: sunjh@ustc.edu.cn) (e.g. sample width effects) on surface flame spread need to be explored. Recent research [3-6] has reported that sample width below a certain threshold value has an important role in flame spread. For surface flame spread, the spread rate is influenced by flame convection and radiation. The convective heat transfer decreases with width while radiation increases with scale. Therefore, when the sample is narrow, convective effects are dominant and flame spread rate should drop. In contrast, in a radiative dominant regime, this rate should rise when sample width is large. For upward flame spread with finite sample width, flame radiation is dominant and the rate of spread increases with sample width [3-5]. However, for horizontal flame spread, opinions as to width effects on spread rate are wide and no consensus has been reached. Flame spread rates over cellulosic samples at small widths of $2-5 \mathrm{~cm}$ were studied in numerical simulations by Mell and Kashiwagi [7], and they found that rates of spread decreased with width. Li et al. [2] performed flame spread experiments over wood surfaces with a larger width range of $2-11 \mathrm{~cm}$, with a width interval of $3 \mathrm{~cm}$, and found the rate of spread increased with sample width. The drop in spread rate with width was not observed in Li's 
experiments, possibly obscured by the large width interval of $3 \mathrm{~cm}$. Experiments of flame spread over polymethyl meth- acrylate (PMMA) at different widths from 2 to $10 \mathrm{~cm}$ were also conducted by Drysdale and MacMillan [8], and their results also showed that the spread rate increased with width. However, the edges of samples in their experiments were protected by sidewalls, which would inhibit the lateral air entrainment and weaken the convective effects, leading to the finding that there would be no drop in spread rate with width. Although flame spread rate should initially drop and then rise with width due to the combined effects of convection and radiation, no similar experimental results have been reported as yet. Clearly, further studies on width effects should be conducted.

In the present work, we describe a series of flame spread experiments over whitewood surfaces that were conducted in a more systematic fashion in Lhasa on the Tibetan Plateau at $3650 \mathrm{~m}$. Sample widths varied from $2 \mathrm{~cm}$ to $12 \mathrm{~cm}$ at intervals of $1 \mathrm{~cm}$. Data on the characteristics of flame spread on a high plateau, that included flame size (flame length and flame height), rate of spread, and flame heat flux, were obtained through experimental measurements, and the influence of sample width on flame spread rates were analyzed.

\section{Experimental apparatus and methods}

Figure 1(a) shows a schematic diagram of the experimental set up. To reduce external disturbances and maintain a quiescent flow field, the sample holder was set in a combustion chamber, which is $1.5 \mathrm{~m}$ in length and $0.7 \mathrm{~m} \times 0.7 \mathrm{~m}^{2}$ in cross- sectional area. A glass window installed in the front wall of the chamber enables the flame shape to be observed more conveniently. Two digital video cameras were used to record the progress of flame spread; one was set outside the observation window, the other at the open door of the com- bustion chamber. A steel rule was fixed to the sample holder to determine the scale of images captured by cameras. A heat flux gauge TS30, with uncertainty of less than $3 \%$, was mounted on the sample surface to measure total flame heat flux onto sample surface. To minimize its influence on flame spread, the heat flux gauge was located 350 $\mathrm{mm}$ from the burner end. As the work temperature could not be greater than $200^{\circ} \mathrm{C}$, the gauge had to be moved further away as the pyrolysis front approached.

Whitewood of uniform texture was used in the series of experiments. The samples were $70 \mathrm{~mm}$ in width, $3 \mathrm{~mm}$ in thickness and $400 \mathrm{~mm}$ in length. Parallel lines were marked at $20 \mathrm{~mm}$ intervals, perpendicular to the direction of spread. The flame propagated along the wood grain. The rate of spread was calculated as an average from all samples over the middle section between $100 \mathrm{~mm}$ to $300 \mathrm{~mm}$, with an uncertainty of $0.4 \mathrm{~mm} / \mathrm{s}$.

To minimize the influence of wood moisture content, samples were kept in a drying oven at constant temperature of $11^{\circ} \mathrm{C}$ and weighed every 2 hours until weights remained constant. The dried samples were taken from the drying oven, wrapped in plastic film, and left in air until their temperatures returned to the ambient temperature. Prepared samples were fixed to the sample holder, as shown in Figure 1(b). At the beginning of each test, one end of the sample was ignited with a line burner, which was removed after about 10 seconds.

Comparative experiments were conducted in Lhasa (plateau) and Hefei (plain). The ambient experimental conditions of these two locations are listed in Table 1.

\section{Results and discussion}

\subsection{Flame shape}

Figure 2 shows 2-cm-wide front and side views of the flame shape during flame spread. The side view is useful to
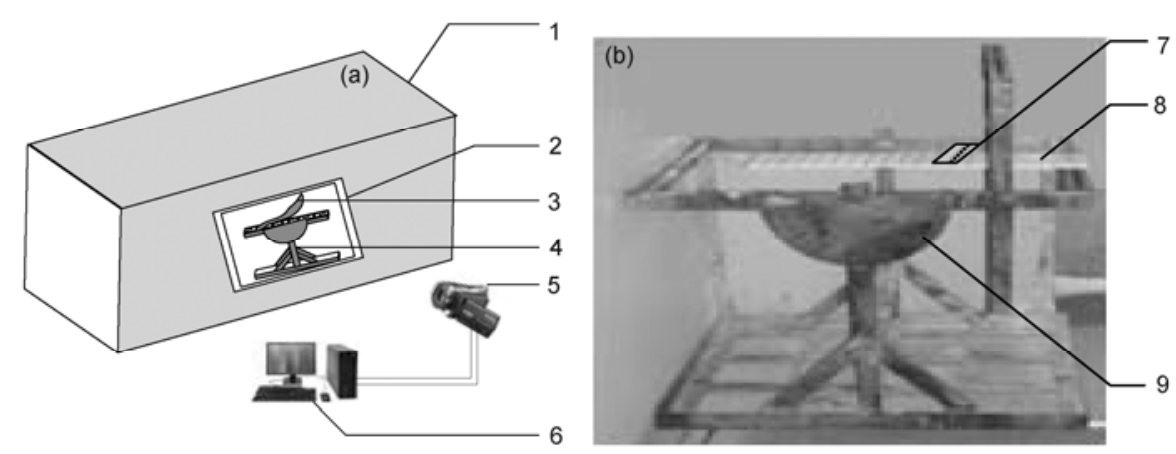

Figure 1 Experimental set-up for flame spread on solid surface. (a) Schematic illustration of the overall experimental system; (b) sample holder. 1, Combustion chamber; 2 , observation window; 3, flame; 4, sample holder; 5 , camera; 6 , computer; 7, heat flux gauge; 8 , sample; 9 , rotary dial.

Table 1 Ambient conditions of experiments on plateau and in plain

\begin{tabular}{|c|c|c|c|c|c|}
\hline Location & Altitude (m) & Atmospheric pressure $(\mathrm{kPa})$ & Absolute oxygen concentration $\left(\mathrm{kg} / \mathrm{m}^{3}\right)$ & Relative humidity (\%) & Ambient temperature $\left({ }^{\circ} \mathrm{C}\right)$ \\
\hline Tibetan Plateau & 3658 & 65.5 & 0.25 & $27-30$ & $25-30$ \\
\hline Hefei plain & 50 & 100.8 & 0.39 & $36-39$ & $23-26$ \\
\hline
\end{tabular}



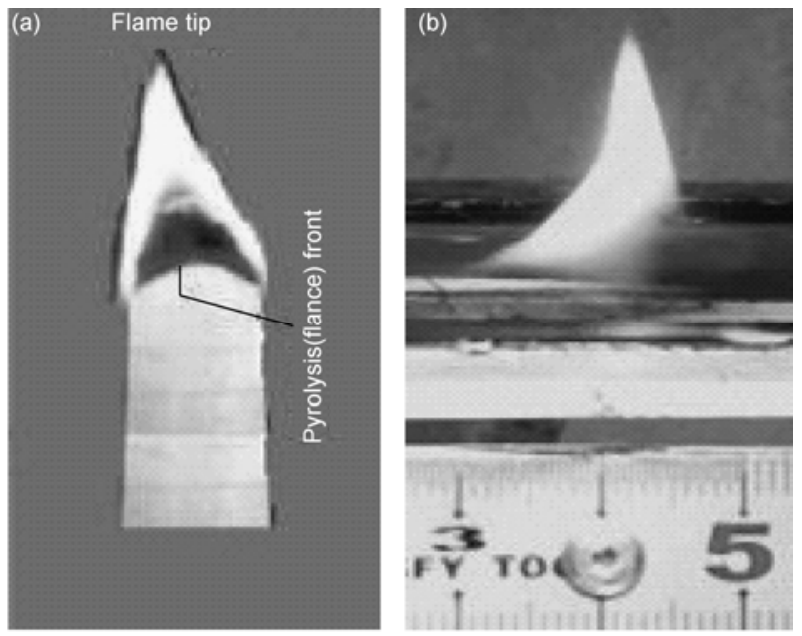

Figure 2 Flame shape of a test with a 2-cm-wide sample. (a) Front view; (b) side view [4].

determine the flame length and flame height. Flame height $H_{\mathrm{f}}$ is defined as the vertical distance between the flame tip and the sample surface; flame length $L_{\mathrm{f}}$ is defined as the horizontal length of luminous zone of the flame (as shown in Figure 2(b)).

Figure 3 shows the development of flame height and length over time in a horizontal flame spread for samples of various widths. Height and length was observed to fluctuate as flame spreading progressed, and the fluctuations were enhanced with sample width. Flame fluctuation is caused by the instability of the boundary layer between flame and ambient air. As the sample widths increase, combustion intensifies and thus fluctuations become more pronounced.

In general, an average flame height and depth are introduced to describe the flame size accounting for the flame fluctuation. Several different ways are used to define the average flame height, and the definition using an intermittence rate is the most widely used. To do this, an intermittence function $I(z)$ is introduced that yields the probability of the flame having size $z$; as an example, $I(z)$ of flame height at $W=3 \mathrm{~cm}$ is plotted in Figure 4 . Given $I(z)$ of flame height, the value of $z$ at which the intermittence rate equals $50 \%$ is defined as the average flame height; similarly, the average flame length for a sample of width $W=3 \mathrm{~cm}$ is also presented in Figure 4.

Average flame heights and lengths for other sample widths were obtained in the same way, and the respective results are presented in Figure 5(a) and (b).

As Figure 5(a) shows, the dimensionless flame height decreased with sample width, where the dimensionless flame height was defined as flame height divided by sample width, viz. $H_{\mathrm{f}} / W$. The diffusion flame height is determined from a combination of buoyancy and the inertial force. In the case of surface flame spread, the height of a buoyant flame is mainly determined by the buoyancy, and the dimensionless flame height follows a power law $H_{\mathrm{f}} / W \sim F_{\mathrm{r}}{ }^{n}$,
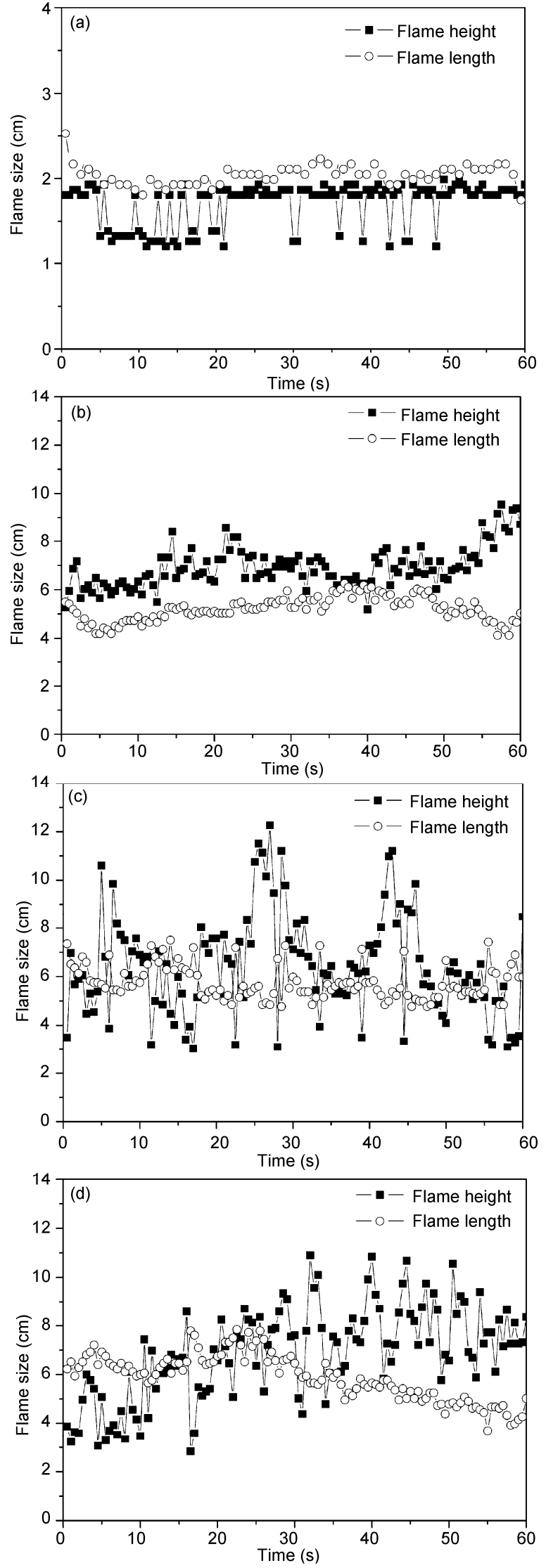

Figure 3 Time evolutions of flame size with various sample widths: (a) $W=3 \mathrm{~cm}$; (b) $W=5 \mathrm{~cm}$; (c) $W=7 \mathrm{~cm}$; (d) $W=9 \mathrm{~cm}$. 


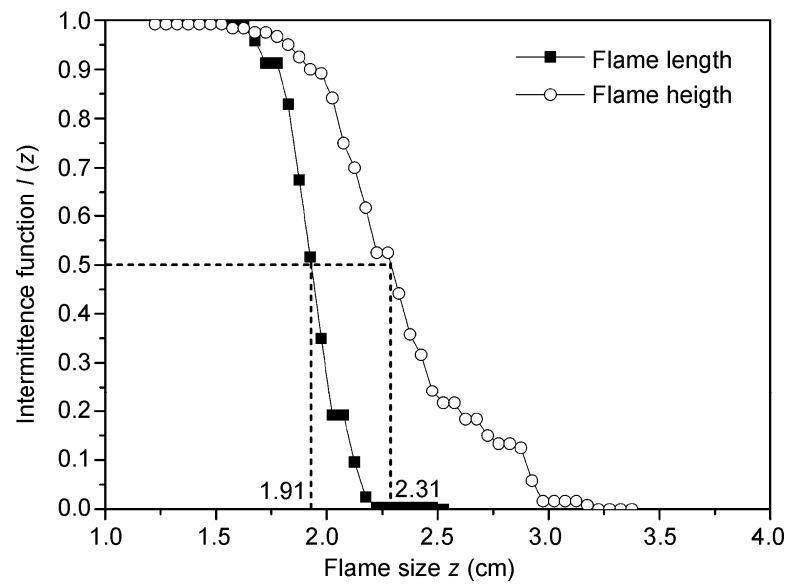

Figure 4 Intermittence function of flame size with a sample width of $3 \mathrm{~cm}$.
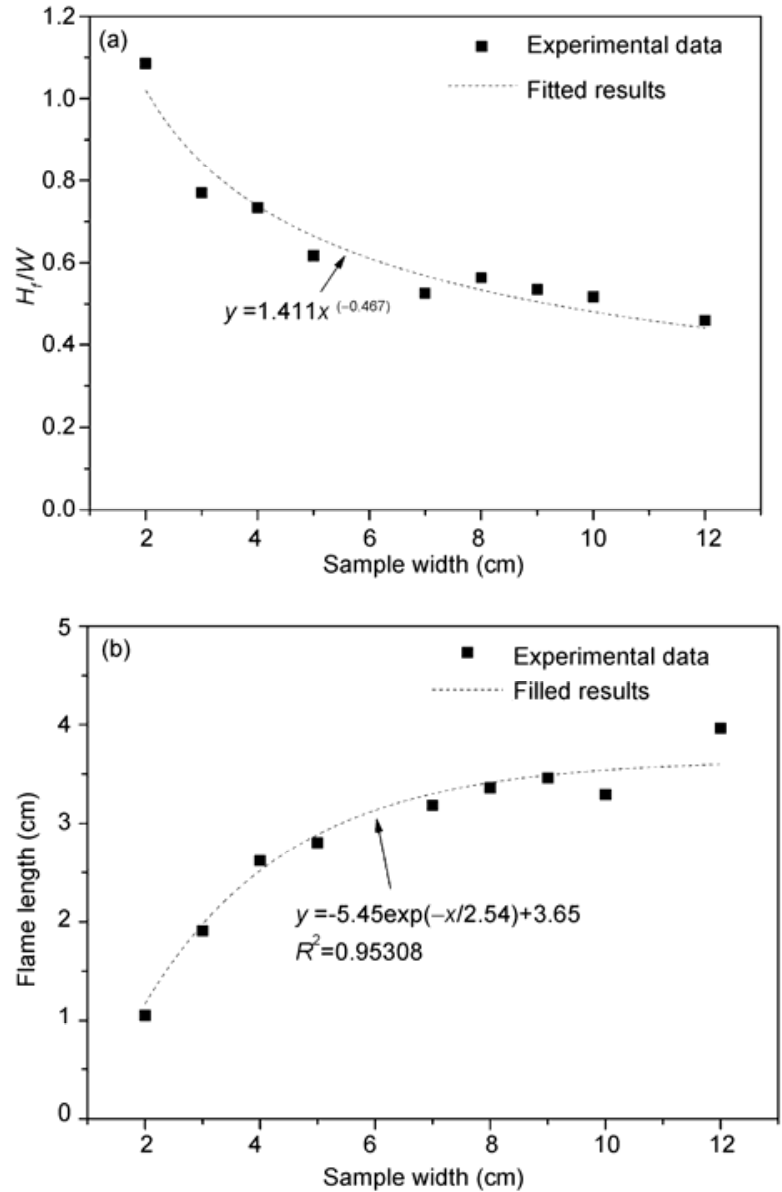

Figure 5 Flame size as a function of sample width. (a) Dimensionless flame height; (b) flame length.

where $F_{\mathrm{r}}=u_{0}^{2} /\left(W_{\mathrm{g}}\right)$ is the Froude number with the exponent constrained by $1 / 5 \leqslant n \leqslant 1 / 3$ [10]. Therefore, the dependence of the dimensionless flame height on sample width should follow the form:

$$
H_{\mathrm{f}} / W \sim W^{-n}, 1 / 5 \leqslant n \leqslant 1 / 3 .
$$

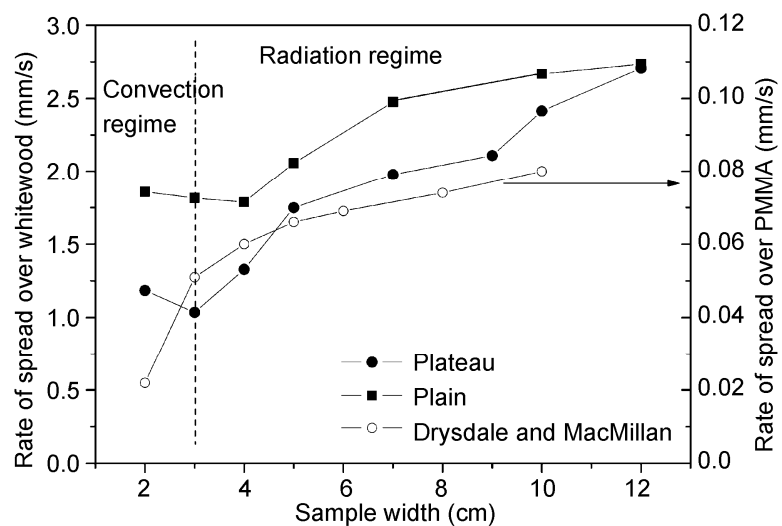

Figure 6 Rate of spread as a function of sample width [8].

The fitted results of experimental data (Figure 5(a)) agreed well with eq. (1) in exhibiting clearly a negative power law dependence on sample width with an exponent of -0.467 . The relationship of flame height to sample width could be put into the following form:

$$
H_{\mathrm{f}}=1.411 W^{0.533}, 2 \mathrm{~cm} \leqslant W \leqslant 12 \mathrm{~cm} \text {. }
$$

Similar with height, flame length also increases with sample width, and the following fitted formula was obtained:

$$
L_{\mathrm{f}}=3.65-5.45 \mathrm{e}^{-W / 2.54}, 2 \mathrm{~cm} \leqslant W \leqslant 12 \mathrm{~cm} \text {. }
$$

\subsection{Rate of flame spread}

Figure 5 shows the experimental data of flame spread rate as a function of sample width. To investigate width effects on the spread rate, two further series of experimental data performed on plains were also analyzed and plotted in Figure 5. One of the series was conducted as comparative study with the same experimental setup, while the other was conducted by Drysdale and MacMillan with a different experimental setup [8]. In Drysdale and MacMillan's experiment, the sides of the samples were protected by two inert sidewalls.

Different spread rate behaviors were found between our study and Drysdale and MacMillan's. Their experimental data showed that the rate of spread over PMMA increased with sample width. Although in our study, the rate rose also with sample width when samples were wider than $3 \mathrm{~cm}$. The rate of spread decreased for $W \leqslant 3 \mathrm{~cm}$. Similar results were also obtained in our comparative experiments; the rate of spread initially showed a slow drop and then increased with sample width. However, the transition point at which the spread rate reached its minimum value occurred at $W=4$ $\mathrm{cm}$, i.e. wider than $3 \mathrm{~cm}$ on the plateau. The difference between the results of Drysdale and MacMillan and this study might be due to the side protection. In Drysdale and MacMillan's experiments, inert sidewalls, not present in our work, were used to inhibit air entrainment from the sides. 
For surface flame spread over a thermally-thick solid, Quintiere [11] proposed that the rate of spread is proportional to the square of flame heat flux onto the unburned surface:

$$
v_{p}=\frac{4\left(\dot{q}_{\mathrm{f}}^{\prime \prime}\right)^{2} \delta_{\mathrm{f}}}{\pi\left(k \rho c_{\mathrm{p}}\right)\left(T_{\mathrm{ig}}-T_{\mathrm{s}}\right)^{2}} .
$$

The width effects on flame spread rate can then be explained by the influence of width on flame heat flux. Time evolutions of flame heat flux onto the unburned surface with various sample widths are shown in Figure 7(a) and their peak values in Figure 7(b).

As observed in Figure 7(b), the development of flame heat flux was found to agree well with that of flame spread rate. As sample width increased, both decreased initially, and when samples were wider than $3 \mathrm{~cm}$, both rose with sample width.

The transition point at $W=3 \mathrm{~cm}$ suggests that surface flame spread with various widths might be controlled by different heat transfer regimes. Flame heat flux to the unburned surface includes two different mechanisms: convective heat transfer and flame radiative transfer. When samples are
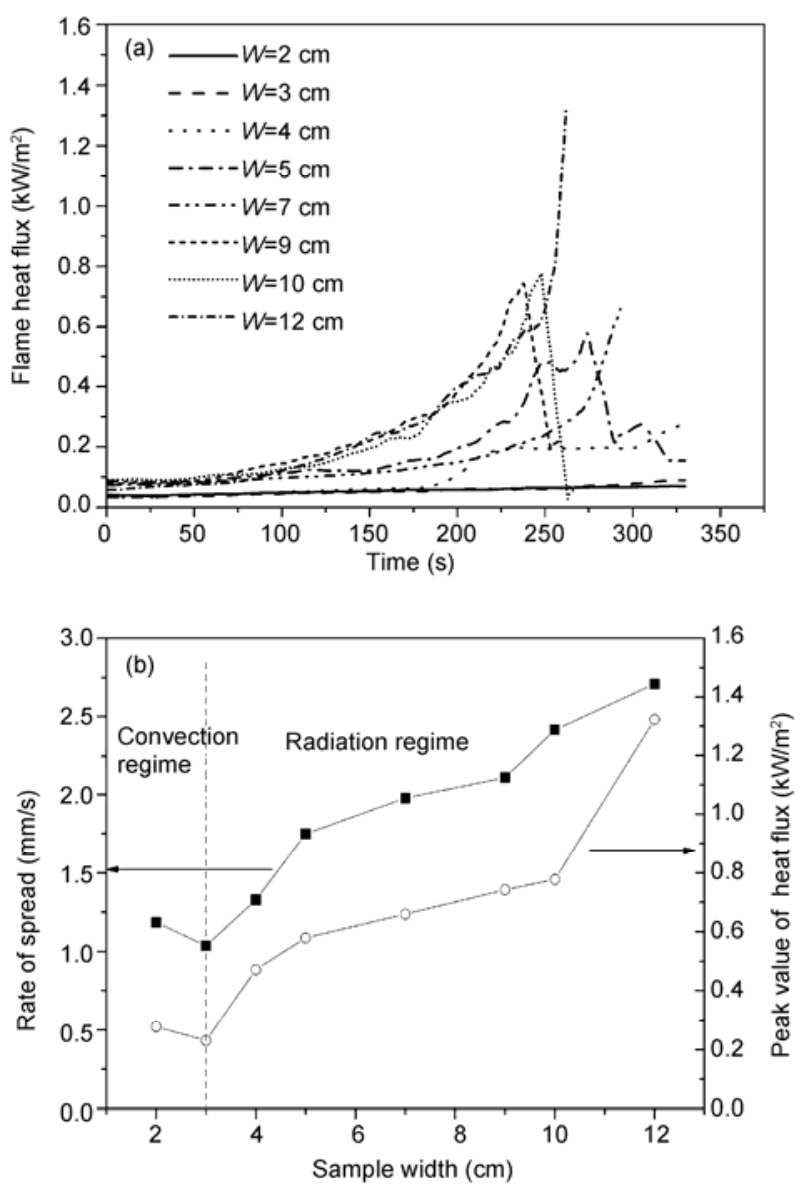

Figure 7 Flame heat flux with various sample widths. (a) Time evolutions; (b) peak values. sufficiently narrow, the lateral entrainment is strong and the convective heat transfer is dominant. The convective heat flux can be described by eq. (5),

$$
\dot{q}_{\mathrm{c}}^{\prime \prime}=h_{\mathrm{c}}\left(T_{\mathrm{g}}-T_{\mathrm{s}}\right) \text {, }
$$

where $h_{\mathrm{c}}$ is the convective flame heat transfer coefficient, and $T_{\mathrm{g}}$ and $T_{\mathrm{s}}$ are the gas and the solid surface temperatures respectively. Quintiere [11] and Modak et al. [12] suggested that the convection coefficient follows a power-law relationship with sample width,

$$
h_{\mathrm{c}} \sim W^{-n} \text {. }
$$

As eqs. (5) and (6) predict, the convective flux decreases with sample width.

As sample width increases, flame radiation becomes more and more important and eventually dominant. The radiation flux obeys the Stefan-Boltzmann law,

$$
\dot{q}_{\mathrm{fr}}^{\prime \prime}(W)=\varepsilon_{\mathrm{f}} \sigma T_{\mathrm{f}}^{4} \cdot F,
$$

in which $\varepsilon_{\mathrm{f}}$ is the flame emissivity, $\sigma$ the Stefan-Boltzmann constant, $T_{\mathrm{f}}$ the flame temperature, and $F$ is the view factor of the flame to the unburned surface. As expected from eqs. (2) and (3), the flame length and flame height would increase with sample width. A larger flame size therefore means a larger view factor. The emissivity, also increases with sample width, can be expressed by the following equation [11],

$$
\varepsilon_{\mathrm{f}} \approx 1-\mathrm{e}^{\kappa W},
$$

where $\kappa$ is the emission coefficient. In consequence, the flame radiation flux increases with sample width.

The width effects on flame spread rate result from the combined influence of convective heat transfer and flame radiation. As analyzed above, flame radiation increases with scale while convection drops as sample width increases. A minimum flame heat flux would be reached as sample width increases, causing a minimum spread rate to be observed at $W=3 \mathrm{~cm}$ on the Tibetan Plateau and at $W=4 \mathrm{~cm}$ on a plain in Hefei. The reason for this larger width at which the transition occurs might be that greater pressure in plains enhance the air entrainment and the convective heat transfer. The fact that no transition from the convection regime to the radiation regime was observed in Drysdale and MacMillan's experiments might be because the inert sidewalls inhibited the lateral air entrainment and weakened the convective effects.

\section{Conclusions}

To explore the characteristics of flame spread over charring solid surface on plateaus, whitewood samples with various widths were chosen as samples in a series of experiments conducted on the Tibetan Plateau. Experimental data of flame spread characteristics (e.g. flame size, rate of spread 
and flame heat flux) on a high plateau were obtained, and the width effect on flame spread rate were analyzed. The main conclusions are summarized in the following.

Flame height and length both increase with sample width. Two fitted formula were obtained for a high plateau that well-describe width effects on these characteristics.

On a high plateau, the rate of spread dropped initially until $W=3 \mathrm{~cm}$ and then increased as sample width increased. The same behavior for flame heat flux with flame spread rate was observed verifying out theoretical deductions. Similar behavior in regard to flame spread rate was observed in comparative experiments on a plain in Hefei, with the rate of spread reaching its minimum value at $W=4 \mathrm{~cm}$ and not $3 \mathrm{~cm}$.

Flame spread over solid surfaces is controlled by two different heat transfer regimes: convective and radiative. The rate of spread dropped in the convective regime and rose in the radiative regime.

This work was supported by the National Natural Science Foundation of China (50976110) and the National Science Foundation for Post-doctoral Scientists of China (20090450703).

1 Wang Y F, Yang L Z, Zhou X J. Experiment study of the altitude ef- fects on spontaneous ignition characteristics of wood. Fuel, 2010, 89: 1029-1034

2 Li J, Ji J, Zhang Y, et al. Characteristics of flame spread over the surface of charring solid combustibles at high altitude. Chinese Sci Bull, 2009, 54: 1957-1961

3 Rangwala A, Buckley S, Torero J. Upward flame spread on a vertically oriented fuel surface: The effect of finite width. Proc Combust Inst, 2007, 31: 2607-2615

4 Pizzo Y, Consalvi J, Querre P, et al. Width effects on the early stage of upward flame spread over PMMA slabs: Experimental observations. Fire Safety J, 2009, 4: 407-414

5 Tsai K, Wan F. Width effect on upward flame spread. Fire Saf Sci, 2005, 8: 409-419

6 Thomas P H, Webster C T. Some experiments on the burning of fabrics and the height of buoyant diffusion flames. Fire Res Note, 1960, 420: 7

7 Mell W, Kashiwagi T. Dimensional effects on the transition from ignition to flame spread in microgravity. Proc Combust Inst, 1998, 27: 2635-2641

8 Drysdale D D, MacMillan A J R. Flame spread on inclined surfaces. Fire Safety J, 1992, 18: 245-254

9 Zhang Y, Sun J H, Ji J, et al. Effects of altitude and sample width on the characteristics of horizontal flame spread over wood sheets. Fire Safety $\mathrm{J}$, in press

10 Williams F A. Combustion Theory. Calif: Benjamin Cummings, 1985

11 Quintiere J. Fundamentals of Fire Phenomena. Chichester: John Wiley \& Sons, 2006

12 Modak A, Croce P. Plastic pool fires. Combus Flame, 1977, 30: 251-265

Open Access This article is distributed under the terms of the Creative Commons Attribution License which permits any use, distribution, and reproduction in any medium, provided the original author(s) and source are credited. 